\title{
Key anatomical structures for safe popliteal node dissection-a rare case series
}

Volume 7 Issue 5 - 2017

\section{Introduction}

Metastasis to the popliteal nodes is a scarce clinical condition which is poorly reported..$^{1-3}$ Consequently, the popliteal lymphadenectomy is a peculiar surgical approach that is not widely discussed in the literature. ${ }^{3-6}$ In the present manuscript, after the successful performance of popliteal node dissection on 17 patients with metastasis to the popliteal basin, the key anatomical structures that guarantee a safe surgical technique are adequately described.

\section{Material \& methods}

During the period 2000-2016, 17 patients presented to our institution for popliteal lymphadenectomy due to metastasis from the primary region to the popliteal nodes. The primary tumors reported in these cases are melanoma, sarcoma and squamous cell carcinoma of the distal lower extremities. Five patients had palpable abnormal popliteal lymph nodes and to the rest of the patients lymphoscintigraphy was performed, showing metastasis to the popliteal basin. (Table

\author{
Arhontoula Xifara, ${ }^{1,2}$ George Skarpas, ${ }^{1,2}$ \\ Maria Zarokosta, ${ }^{1,2}$ Menelaos Zoulamoglou,' \\ Theodoros Piperos, ${ }^{1,2}$ loannis Papanastasiou, ' \\ loannis Flessas, I Theodoros Mariolis- \\ Sapsakos ${ }^{1,2}$ \\ 'Department of Surgery, General and Oncologic Hospital of \\ Kifissia Agii Anargiri, University of Athens, Greece \\ ${ }^{2}$ Anatomy, Histology \& Embryology Laboratory, Nursing School, \\ University of Athens, Greece
}

Correspondence: GA Skarpas MD, PhD, Consultant Orthopaedic Surgeon/Lecturer of Anatomy, University of Athens, School of Nursing, Athens, Greece, 20 Papadiamandopoulou Str., Athens, Greece Tel: +302107208100; +306942465650; Email skarpasg@hotmail.com

Received: January 29, 2017| Published: March 31, 2017

1) The rare surgical procedure of the popliteal node dissection was successfully performed to all these patients and therefore its technique is descriptively mentioned.

Table I Descriptions concerning the patients involved in the present study

\begin{tabular}{|c|c|c|c|c|c|c|c|c|}
\hline $\begin{array}{l}\text { Acral primary } \\
\text { tumor }\end{array}$ & $\begin{array}{l}\text { Palpable } \\
\text { popliteal } \\
\text { nodes }\end{array}$ & Lymphoscintigraphy & $\begin{array}{l}\text { Positive } \\
\text { popliteal } \\
\text { nodes at } \\
\text { lym/phy }\end{array}$ & $\begin{array}{l}\text { Positive } \\
\text { inguinal } \\
\text { nodes at } \\
\text { lym/phy }\end{array}$ & $\begin{array}{l}\text { Positive } \\
\text { nodes of } \\
\text { the pelvis } \\
\text { at lym/phy }\end{array}$ & Incision type & $\begin{array}{l}\text { Postoperative } \\
\text { complications }\end{array}$ & $\begin{array}{l}\text { End of } \\
\text { follow-up }\end{array}$ \\
\hline $\begin{array}{l}\text { Melanoma } \\
n=\mid I\end{array}$ & $n=2$ & $\mathrm{YES}=9$ & YES =9 & $\mathrm{YES}=4$ & $\mathrm{YES}=2$ & $\begin{array}{l}\text { Vertical } n=5 \\
\text { S-Shape } n=6\end{array}$ & $\begin{array}{l}\text { Cellulitis } n=3 \text { Traum } \\
\text { infection } n=1 \\
\text { Lymphoedema } n=3 \\
\text { Delayded removal of } \\
\text { the drainage } n=8\end{array}$ & $\begin{array}{l}\text { aAlive with } \\
\text { disease } \\
n=7 \\
\text { Dead with } \\
\text { disease } n=4\end{array}$ \\
\hline $\begin{array}{l}\text { Squamous cell } \\
\text { carcinoma } n=5\end{array}$ & $n=2$ & $Y E S=3$ & $Y E S=3$ & $\mathrm{YES}=2$ & YES = I & $\begin{array}{l}\text { Vertical } n=3 \\
\text { S-Shape } n=2\end{array}$ & $\begin{array}{l}\text { Lymphoedema } n=3 \\
\text { Delayded removal of } \\
\text { the drainage } n=4\end{array}$ & $\begin{array}{l}\text { Alive with } \\
\text { disease } \\
\mathrm{n}=4 \\
\text { Dead with } \\
\text { disease } \\
\mathrm{n}=1\end{array}$ \\
\hline Sarcoma $n=I$ & $n=1$ & NO & - & - & - & $\begin{array}{l}\text { Vertical } \quad n=1 \\
\text { S-Shape } n=0\end{array}$ & $\begin{array}{l}\text { Delayded removal of } \\
\text { the drainage } \\
n=1\end{array}$ & $\begin{array}{l}\text { Alive with } \\
\text { disease } \\
\mathrm{n}=\mathrm{I}\end{array}$ \\
\hline
\end{tabular}

\section{Technique presentation}

The popliteal lymphadenectomy was performed on the patient placed in prone position and his/her knee a little flexed. On the ten first patients, a typical S-shape incision was made. On the rest of the patients though, the surgeons modified the incision to a vertical one in order to gain better exposure and access to the popliteal fossa. Afterwards, the incision was created till the level of Scarpa's fascia and the skin flaps were developed until the formation of a diamond's shape operative field. The popliteal fascia was exposed and the neurovascular bundle was identified; following this, the surgeons gently ligated and divided the superficial lesser saphenous vein and retracted some little cutaneous terminal nerve branches. Then, they approached the operative field close to the lateral skin flap, which exposed proximally the lateral head of the biceps femoris muscle that was meticulously dissected. Medially to the edge of the lateral head of this muscle, $1.15 \mathrm{~cm}$ deeper to its surface, the common peroneal nerve was detected. The common peroneal nerve is a key anatomical structure when performing popliteal lymphadenectomy since it is an easily detected superficial structure and its identification leads to easier detection of the popliteal vessels, lying beneath it and of the tibial nerve-is a key point for a safe procedure. Once detected, the surgeons dissected the common peroneal nerve meticulously to avoid its division that could lead to club foot. Then, the surgeons continued ascending dissection in order to detect the origin of the common 
peroneal nerve, the sciatic nerve. The identification of the last one key anatomical structure, subsequently enables the easier and safer dissection of the tibial nerve within the popliteal basin. The surgeons retracted the sciatic nerve carefully with a vessel loop. (Figure $1 \& 2$ ) Subsequently, the tibial nerve was gently isolated. Thus, its surgical injury could provoke loss of sensibility of the lateral surface of the calf, the plantar surface of the foot and inability of plantar flexion. After these maneuvers, the surgeons could proceed in deeper structures.
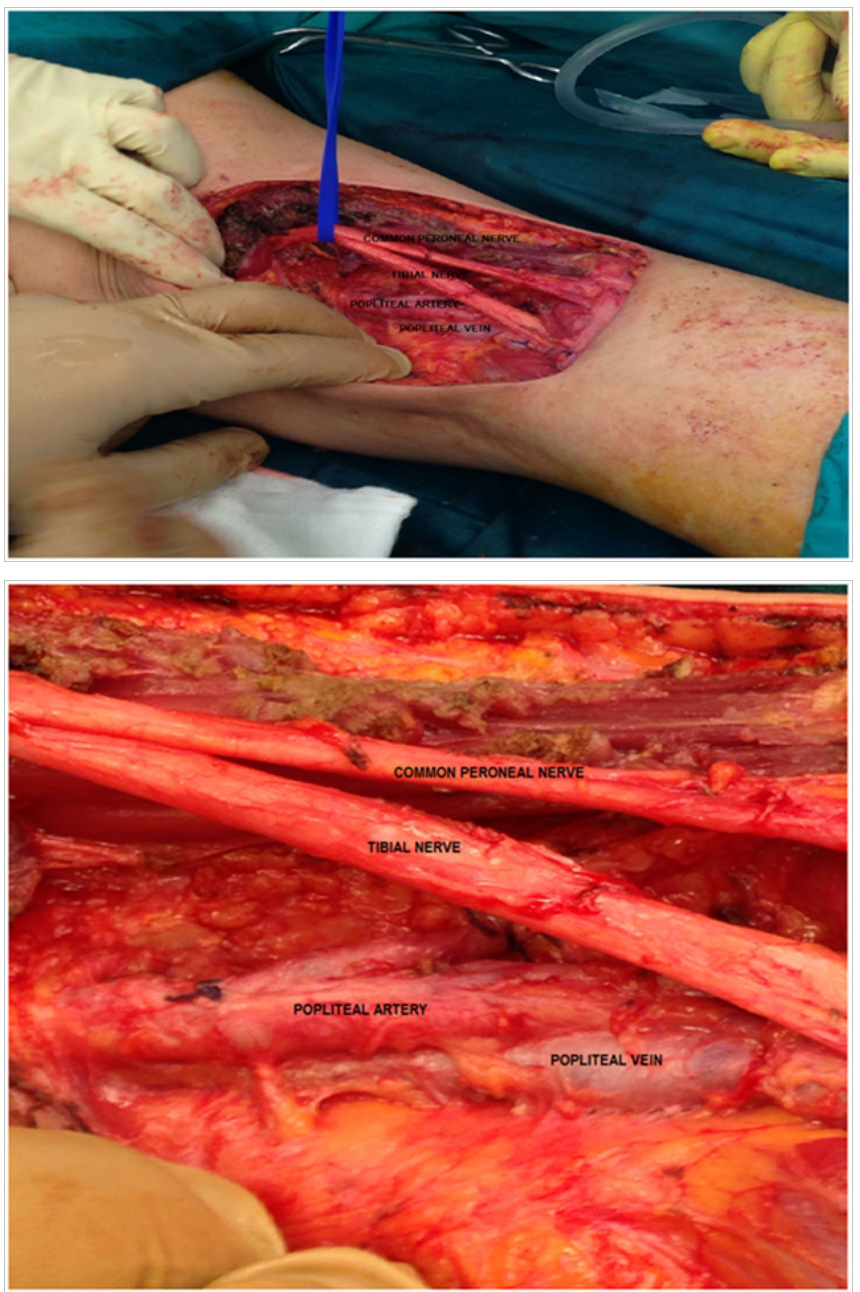

Figure 1\&2 The sciatic nerve bifurcating in the common peroneal and the tibial nerve. This key anatomical structure is retracted. Beneath the nerves popliteal vessels are exposed.

Next, they retracted the lateral cutaneous sural nerve that originates from the peroneal nerve and the medial cutaneous sural nerve that originates from the tibial nerve. The retraction of all the previous nerves permitted the safe approach of the popliteal vessels. The popliteal artery is slightly deeper and medial with respect to the vein. (Figure 3) Once these major vessels have been gently hooked with vessel loops and retracted, the surgeons could access the deepest popliteal nodes without any risk of surgical injury of the keysignificance anatomical structures.

The 2-6 popliteal lymph nodes and the surrounding fatty tissue were carefully removed along, below and superficially to the neurovascular bundle. Afterwards, the popliteal space was inspected and palpated for the identification of any left abnormal lymph nodes that should be removed. Prompt hemostasis was conducted as well. Then, the deep fascia was restorated with a running 2-0 absorbable suture and a closed suction drain was placed over it. Finnally the the skin was closed-sutured. The patients were in general discharged the 5 th postoperative day, when the suction drain was removed.

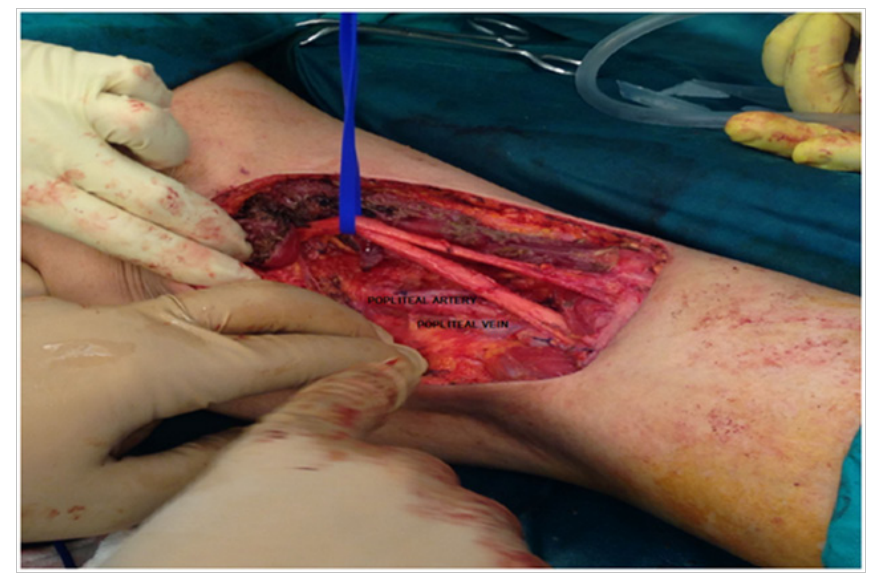

Figure 3 The popliteal artery located slightly deeper and medial with respect to the popliteal vein.

At this point, it should be mentioned that in 12 patients lymphoscintigraphy was made and showed major uptake of radionuclide in the popliteal basin in all these patients. In 6 patients radionuclide was also detected in the groin. In these patients apart from popliteal lymphadenectomy, inguinal node dissection was performed as well. Finally, in 3 patients except for the previous anatomical regions, the gamma probe identified complementary uptake of the radionuclide in the pelvis and so lymph node dissection was conducted, as essential.

\section{Discussion}

The popliteal lymph nodes are embedded below the muscle fascia in the popliteal fossa. ${ }^{7}$ They are 2-6 small nodes that lie within the fatty tissue which surrounds the major vessels and the nerves of the popliteal basin. ${ }^{6,8}$ They can be detected ventrally, dorsally and laterally with respect to the popliteal vessels and so surgical maneuvers in this anatomical region must be careful.

Popliteal lymph nodes collect the lymph from anatomical areas of the lower extremity such as the lateral aspect of the sole, the calf, the heel, the fifth toe, the Achilles tendon area, the anterior part of the leg and of the dorsum. ${ }^{9-11}$ The lymphatic drainage to the popliteal fossa is relatively infrequent and poorly described in the literature, with a general incidence of $6.9-9 \%{ }^{4,6,9}$ For clinical reasons though, it is highly important to mention that in cases of popliteal lymphatic drainage, three patterns can be detected. The first one is the serial drainage pattern, in which lymph from the popliteal nodes runs into the groin. In the rest of the patterns, lymph drains parallel to the popliteal basin and the groin and it may or may not drain into the inguinal nodes as well. ${ }^{2}$

Metastasis to the nodes of the popliteal fossa can be diagnosed during clinical examination or by the use of sentinel lymph node procedure. Its occurrence is scarce and it is rarely reported in the literature. ${ }^{1-3}$ This paucity of reports may be explained as follows. Principally, there is a tendency to avoid clinical examination of the popliteal basin, although its palpation is fundamental and of major importance for the detection of abnormal lymph nodes. ${ }^{1,6,9}$ Secondly, even when physical examination is performed, metastasis to the popliteal nodes might be missed, because they lie beneath the powerful popliteal fascia and they might not be palpated promptly. ${ }^{1}$ Additionally, some surgeons, unfortunately avoid examining the 
popliteal basin even during lymphoscintigraphy, and after examining tumor's primary site, emphasize straight to the inguinal nodes. ${ }^{6}$ In fact, popliteal lymph nodes are reported as first order sentinel nodes due to squamous cell carcinoma and sarcoma of the distal foot. ${ }^{8,12,13}$ Most frequently in the literature, as in the present manuscript, popliteal node metastasis is related with malignant melanoma of the distal foot. Nevertheless, its prevalence is extremely rare, referred only in an average of $0.31 \%$ of patients. ${ }^{3}$

Consequently, surgeons rarely do encounter a popliteal node dissection in the clinical practice. ${ }^{1,5}$ Therefore, there are just a few reports concerning its surgical technique in the literature. ${ }^{3,6}$ Regarding the technique, the incisions suggested are S-shape or Z-plasty. ${ }^{5}$ In the present manuscript, the incision was modified to a vertical one, allowing better exposure of the structures of the popliteal basin and more mediate approach of the key anatomical structure of the common peroneal nerve. Identification of the common peroneal nerve and of its origin, the sciatic nerve, as performed in this study, guarantees the safe detection of the superficial tibial nerve and the avoidance of its traumatic division or of the injury of the popliteal vessels beneath it. Last but not least, the sciatic nerve and the major vessels should be retracted with vessel loops so that surgeons can safely remove the popliteal lymph nodes lying within the fatty tissue close to the neurovascular bundle. At this point, the clinical significance of inspection and palpation of the popliteal space for the identification of abnormal lymph nodes should be underlined.

Although rare as an operation, popliteal lymphadenectomy is the treatment of choice in cases of localized clinical or microscopic disease. ${ }^{13-15}$ Prophylactic dissection of the popliteal nodes is not considered necessary. ${ }^{3,6}$ Still, the survival after this operation is not elucidated due to its rarity. ${ }^{1,7}$ In the present manuscript, the operation had both therapeutic and prognostic value for the patients with acral primary tumour.

\section{Conclusion}

Conclusively, popliteal node dissection is the adequate therapeutic procedure in case of metastasis to the popliteal fossa from acral primary tumors. The frequency though of this surgical procedure is typically low and consequently surgeons are not adequately trained. Therefore, surgeons' knowledge concerning the approach of the key anatomical structures that can guide them during the removal of the popliteal nodes is pivotal and fundamental for the performance of popliteal lymphadenectomy without hazardous impacts to the patient.

\section{Acknowledgments}

None.

\section{Conflicts of interest}

None.

\section{References}

1. Sholar A, Martin RC, McMasters KM Popliteal lymph node dissection. Ann Surg Oncol. 2005;12(2):189-193.

2. Morcos B1, Al-Ahmad F Metastasis to the popliteal lymph nodes in lower extremity melanoma and their management. Surg Oncol. 2011;20(2):e119-e122.

3. Georgeu G1, El-Muttardi N, Mercer D Malignant melanoma metastasis to the sentinel node in the popliteal fossa. Br J Plast Surg. 2002;55(5):443-445.

4. Teixeira F, Moutinho V, Akaishi E et al. Popliteal lymph node dissection for metastases of cutaneous malignant melanoma. World J Surg Oncol. 2014; $12: 135$.

5. Barrasa Shaw A, Sancho Merle F, Fuster Diana C et al. Popliteal lymphadenectomy on sentinel lymph node melanoma metastasis. Clin Transl Oncol. 2006;8(3):218-220.

6. Thompson JF, Hunt JA, Culjak G et al. Popliteal lymph node metastasis from primary cutaneous melanoma. Eur J Surg Oncol. 2000;26(2):172-176.

7. Kretschmer L, Sahlmann CO, Bardzik P et al. The popliteal fossa - a problem zone for sentinel lymphonodectomy. J Dtsch Dermatol Ges. 2011;9(2):123-127.

8. Nishida Y, Yamada Y, Tsukushi S et al. Sentinel lymph node biopsy reveals a positive popliteal node in clear cell sarcoma. Anticancer Res. 2005;25(6C):4413-4416.

9. Menes TS, Schachter J, Steinmetz AP et al. Lymphatic drainage to the popliteal basin in distal lower extremity malignant melanoma. Arch Surg. 2004;139(9):1002-1006.

10. Roozendaal GK, de Vries JD, van Poll D et al. Sentinel nodes outside lymph node basins in patients with melanoma. Br J Surg. 2004;88(2):305-308.

11. Tanaka K, Mori H, Okazaki M, Nishizawa A et al. Long-term treatment outcome after only popliteal lymph node dissection for nodal metastasis in malignant melanoma of the heel: the only "interval node" dissection can be an adequate surgical treatment. Case Rep Oncol Med. 2013;2013:259-326.

12. Hatta N, Morita R, Yamada M et al. Implications of popliteal lymph node detected by sentinel lymph node biopsy. Dermatol Surg. 2005;31(3):327-330.

13. Ozçelik D, Tatlidede S, Hacikerim S et al.The use of sentinel lymph node biopsy in squamous cell carcinoma of the foot: a case report. J Foot Ankle Surg. 2005;43(1):60-63.

14. Steen ST, Kargozaran H, Moran CJ et al. Management of popliteal sentinel nodes in melanoma. J Am Coll Surg. 2011;213(1):180-186.

15. Costa SR, Horta SH, Henriques AC Popliteal lymphadenectomy for treating metastatic melanoma: case report. Sao Paulo Med J. 2008;126(4):232-235. 